
\title{
Analisis Perbandingan Metode Alpha Miner, Inductive Miner dan Causal-Net Mining dalam Proses Mining
}

\author{
Rissa Aulia Hasyim \\ Jurusan Teknik Informatika \\ Universitas Islam Negeri Maulana \\ Malik Ibrahim \\ Malang, Indonesia \\ 17650044@student.uin-malang.ac.id
}

\author{
Muhammad Ainul Yaqin \\ Jurusan Teknik Informatika \\ Universitas Islam Negeri Maulana \\ Malik Ibrahim \\ Malang, Indonesia \\ yaqinov@ti.uin-malang.ac.id
}

\author{
Adi Heru Utomo \\ Jurusan Teknologi Informasi \\ Politeknik Negeri Jember \\ Jember, Indonesia \\ adiheruutomo@polije.ac.id
}

Abstract-Not all process mining algorithms can detect all model process scenarios, so experiments are carried out by trying 3 types of algorithms against 9 business process model scenarios in order to find the most suitable algorithm for each process model scenario. We use 3process algorithms mining including alpha miner, inductive miner and causal-net mining. We propose a solution using the ProM application to check the suitability of the 3 algorithms used against 9 scenarios. In addition, to support the results of the mining process using ProM, we measure the similarity value by comparing the process model on the dataset with the results of the mining process using ProM. Based on the similarity measurement, it is known that the experiment uses algorithm alpha miner. Figure 8 has the highest similarity level with a value of 0.89 . While the smallest level of similarity is found in Figure 7 using alpha miner with a value of 0.12 .

Keywords-Process mining, discovery, alpha miner, inductive miner, causal-net mining, similarity.

Abstrak - Tidak semua algoritma proses mining dapat mendeteksi semua skenario model proses, sehingga dilakukan eksperimen dengan mecoba 3 jenis algoritma terhadap 9 skenario model proses bisnis yang bertujuan untuk mendapatkan algoritma yang paling cocok untuk setiap skenario model proses. Kami menggunakan 3 algoritma proses mining diantaranya alpha miner, inductive miner dan causal-net mining. Kami mengusulkan solusi dengan menggunakan aplikasi ProM untuk mengecek kecocokan 3 algoritma yang digunakan terhadap 9 skenario. Selain itu, untuk mendukung hasil proses mining menggunakan ProM, kami mengukur nilai similarity dengan membandingkan model proses pada dataset dengan hasil proses mining menggunakan ProM. Berdasarkan hasil pengukuran similarity diketahui bahwa eksperimen menggunakan algortima alpha miner. Pada figure 8 memiliki nilai tingkat similarity paling tinggi yaitu dengan nilai 0.89 . Sedangkan tingkat similarity paling kecil, didapati pada figure 7 menggunakan alpha miner dengan nilai 0.12 .

Keywords-Proses mining, discovery, alpha miner, inductive miner, causal-net mining, similarity.

\section{PENDAHULUAN}

Proses mining adalah proses mendapatkan informasi dari basis data dalam bentuk pola menggunakan metode tertentu. Proses mining merupakan cara untuk mendapatkan informasi baru dan objektif tentang proses bisnis yang sedang dilaksanakan oleh suatu organisasi. Proses mining dapat dilakukan dengan mengambil data nyata atau event log, kemudian memeriksa kesesuaian event log terhadap proses bisnis [1].

Ada tiga jenis proses mining yaitu: discovery (penemuan), conformance (kesesuaian) dan enhancement (peningkatan). Adapun penjelasan untuk masing masing jenis proses mining sebagai berikut [2].

1) Discovery

Discovery adalah proses mining tanpa melibatkan model proses. Model proses bisnis ini hanya terbentuk dari event log yang sudah tersedia. Cara kerja dari teknik discovery adalah menganalisis suatu event log dan kemudian dari event log teknik ini akan memuat sebuah model tanpa menggunakan informasi yang apriori. Teknik ini merupakan teknik yang paling sering digunakan dari proses mining.

2) Conformance

Conformance merupakan model proses yang terlibat. Tujuan dari conformance adalah untuk memeriksa apakah model yang telah ada sesuai dengan yang terjadi pada kenyataan atau sebaliknya. Aplikasi conformance checking sangatlah luas, dapat dilakukan pada model prosedural, model organisasi, kebijakan bisnis dan lainlain.

3) Enhancement

Enhancement juga melibatkan sebuah model proses, model yang ada diperluas dengan aspek yang baru. Tujuannya yaitu untuk memperkaya atau memperluas model yang sudah ada dengan informasi yang didapat dari event log di dunia nyata, dan untuk mengganti atau menambah model apriori. Sebagai contoh: menggunakan timestamp pada event log dapat memperluas model sehingga dapat menunjukkan dimana terjadi bottleneck, kepuasan pelayanan, waktu eksekusi dan frekuensi.

Adapun beberapa algoritma discovery dalam proses mining sebagai berikut.

a) Alpha miner adalah algoritma yang digunakan dalam proses mining, yang bertujuan untuk merekonstruksi kausalitas dari serangkaian event log. Algoritma alpha miner didefinisikan dalam istilah Petri Nets (Place/Transition Nets). Algoritma ini pertama kali dikemukakan oleh "van der Aalast", seorang profesor di Departemen Matematika dan Ilmu Komputer dari Technische Universiteit Eindhoven (TU/e) [3].

b) Inductive Miner adalah algoritma yang menambang pohon proses dari event log. Pendekatan algoritma Inductive Miner bekerja secara rekursif, yaitu membagi dan menaklukkan: membagi log (split log), kemudian membangun bagian dari proses tree. Kemudian proses akan dilanjutkan dengan menangani bagian log yang terbelah secara terpisah. Algoritma dikatakan bagus 
saat berurusan dengan log besar dan berisi perilaku unik [4].

c) Causal-net (C-net) adalah grafik di mana node mewakili aktivitas dan busur mewakili dependensi kausal. Setiap aktivitas memiliki satu set binding input yang mungkin dan satu set binding output yang mungkin [5].

d) Heuristics Miner adalah algoritma yang menggunakan pendekatan heuristik. Menurut Weijters [4] algoritma heuristic miner memiliki tiga langkah utama, yaitu: (1) membuat grafik dependensi, (2) membuat tanda input dan output untuk setiap aktivitas dan (3) mencari hubungan ketergantungan jarak jauh. Hasil penelitian Weber [4] menunjukkan bahwa heuristic miner merupakan algoritma yang tangguh dalam menangani jenis kebisingan tertentu.

Tidak semua algoritma proses mining dapat mendeteksi semua skenario model proses, sehingga dilakukan eksperimen dengan mecoba 3 jenis algoritma terhadap 9 skenario [6] model proses bisnis yang bertujuan untuk mendapatkan algoritma yang paling cocok untuk setiap skenario model proses. Kami menggunakan 3 algoritma proses mining diantaranya alpha miner, inductive miner dan causal-net mining.

Beberapa penelitian terkait proses mining yang sudah pernah dilakukan sebelumnya. Antara lain, Accorsi [7] menjelaskan potensi proses mining sebagai dasar untuk audit keamanan proses bisnis dan sistem manajemen proses bisnis yang sesuai. Secara khusus, ini berfokus pada proses discovery sebagai sarana untuk merekonstruksi struktur terkait proses dari event log, seperti aliran kontrol proses, jaringan sosial, dan aliran data. Berdasarkan informasi ini, analisis keamanan untuk menentukan kepatuhan terhadap persyaratan keamanan dan privasi dapat diotomatiskan. Selain itu, Aalst [8] melakukan penelitian dalam upaya pengujian conformance untuk mengukur 'fit' antara event log dan beberapa model proses yang telah ditentukan sebelumnya. Dalam makalah ini, peneliti menunjukkan bahwa analisis Delta dan pengujian confermance dapat digunakan untuk menganalisis penyelarasan bisnis selama actual event dicatat dan user memiliki kendali atas proses tersebut. Selanjtnya, Caldeira [9] melakuka penelitian yang bertujuan untuk memberikan wawasan baru tentang proses pengembangan perangkat lunak dengan menganalisis cara pengembang menggunakan IDE mereka. Berdasarkan teknik proses mining seperti proses discovery dan confermance checking, perspektif yang hilang ini diharapkan akan memungkinkan penemuan pola pengkodean, pencarian perilaku programmer, dan deteksi penyimpangan dari proses yang ditentukan. peneliti berharap dapat memberikan saran untuk peningkatan proses perangkat lunak individu.

Pada penelitian ini, kami meggunakan discovery untuk melakukan proses mining, karena diketahui bahwa proses discovery dibangun dari bawah ke atas khusus untuk RPA itulah sebabnya proses discovery memberikan yang lebih cepat, lebih fleksibel, pendekatan yang lebih komprehensif, dan lebih hemat biaya untuk secara otomatis mengidentifikasi dan menganalisis proses kerja otomatis.

Kami mengusulkan solusi dengan menggunakan aplikasi ProM untuk mengecek kecocokan 3 algoritma yang digunakan terhadap 9 skenario. Selain itu, untuk mendukung hasil proses mining menggunakan ProM, kami mengukur nilai structural similarity dengan membandingkan model proses pada dataset dengan hasil proses mining menggunakan ProM.

\section{METODE PENELITIAN}

Metodologi penelitian yang diimplementasikan terbagi kedalam beberapa tahapan, ditunjukkan pada prosedur penelitian pada Gambar. 1 sebagai berikut.

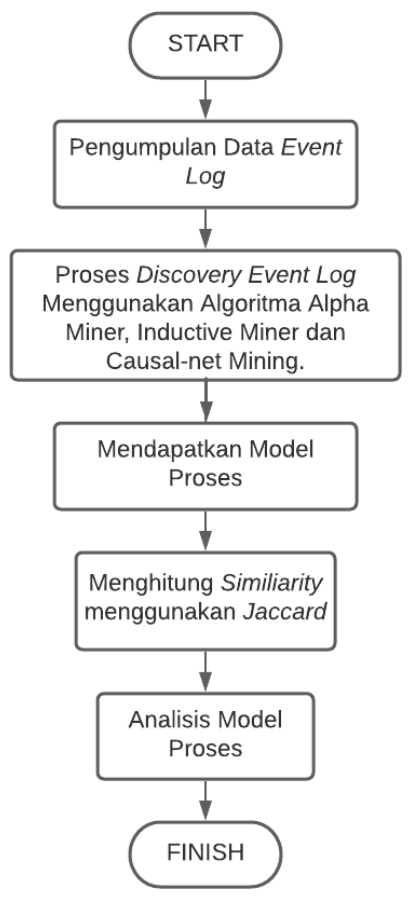

Gambar. 1. Prosedur Penelitian

Pada penelitian ini kami menggunakan dataset yang terdiri dari beberapa model proses bisnis [6].

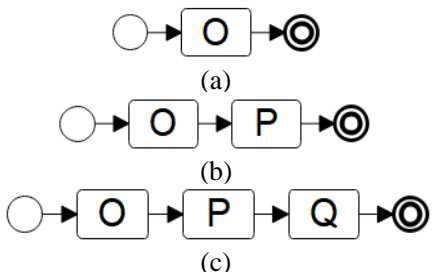

Gambar. 2. Model proses bisnis sequence

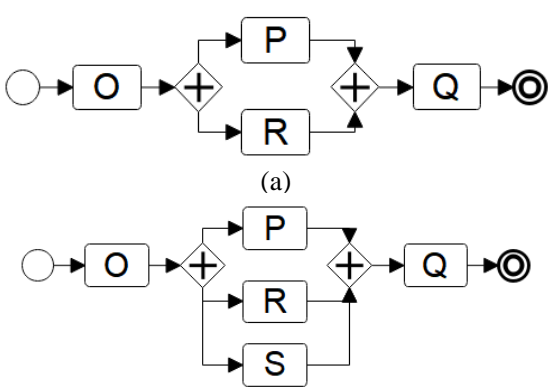

(b)

Gambar. 3. Model proses bisnis dengan cabang AND

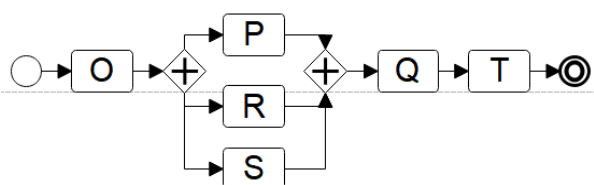




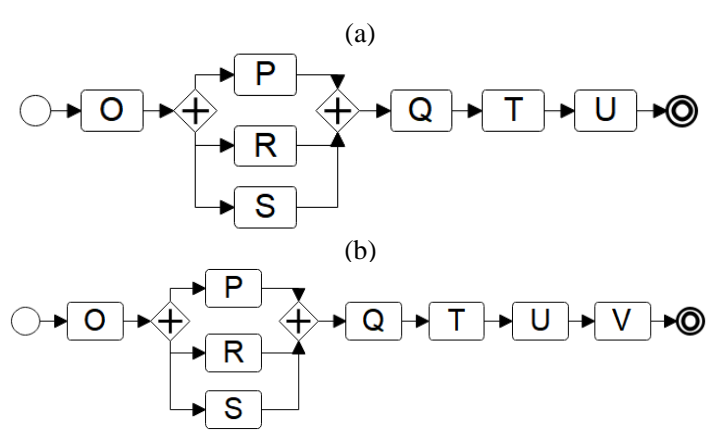

(c)

Gambar. 4. Model proses bisnis sequence dengan penambahan kegiatan
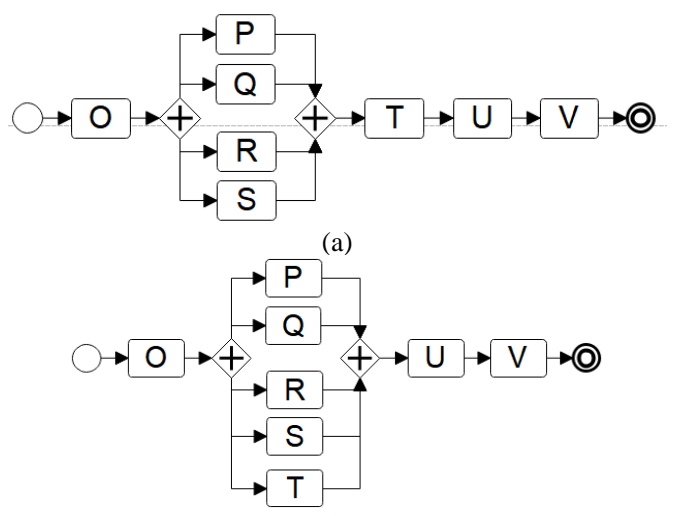

(b)

Gambar. 5. Model proses bisnis dengan variasi jumlah cabang.

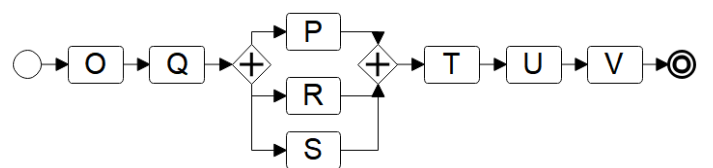

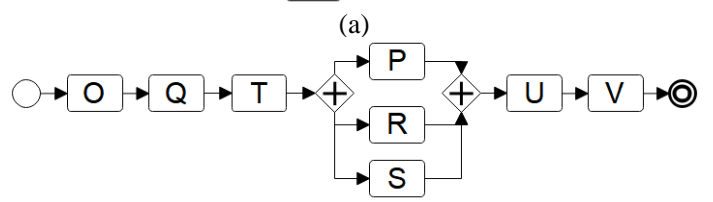

(b)

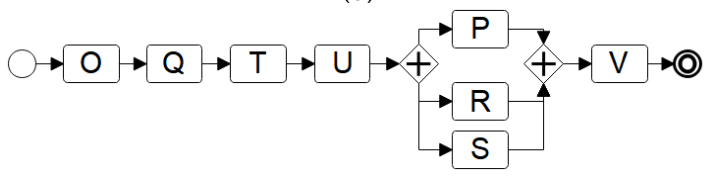

(c)

Gambar. 6. Model proses bisnis dengan variasi posisi bercabang.

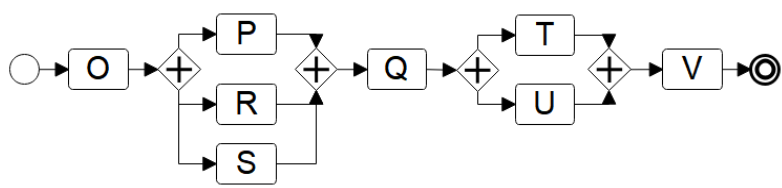

(a)

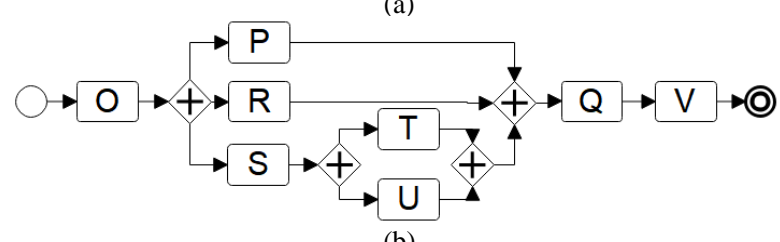

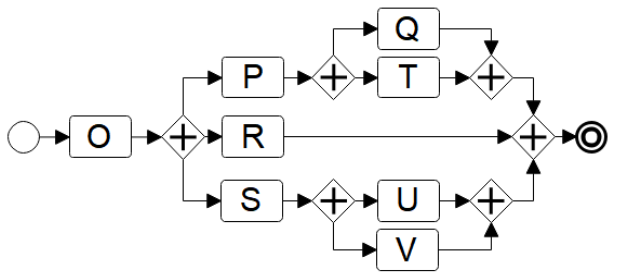

(c)

Gambar. 7. Model proses bisnis dengan variasi kedalaman percabangan.

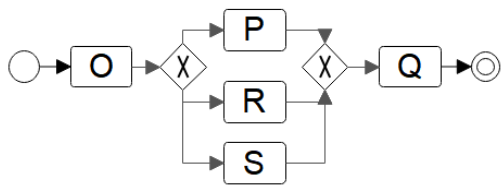

$$
\begin{aligned}
& \text { (a) }
\end{aligned}
$$

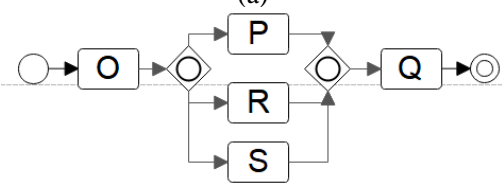

Gambar. 8. Model proses bisnis dengan variasi jenis percabangan.

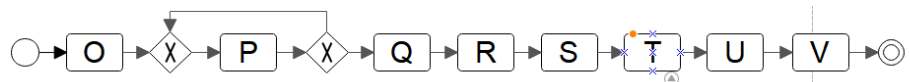

$O \rightarrow O \rightarrow x \rightarrow P \rightarrow Q \rightarrow x \rightarrow R \rightarrow S \rightarrow T \rightarrow U \rightarrow U \rightarrow(0)$

$O \rightarrow O, x \rightarrow P, Q \rightarrow R \rightarrow x \rightarrow U, T \rightarrow U \rightarrow U \rightarrow(0$ (c)

$O \rightarrow O \rightarrow X \rightarrow P \rightarrow Q \rightarrow R \rightarrow S \rightarrow x \rightarrow T \rightarrow U \rightarrow V \rightarrow(0$ (d)

$\mathrm{O} \rightarrow \mathrm{x} \rightarrow \mathrm{P} \rightarrow \mathrm{x} \rightarrow \mathrm{R} \rightarrow \mathrm{S} \rightarrow \mathrm{T} \rightarrow \mathrm{U} \rightarrow \mathrm{V} \rightarrow 0$

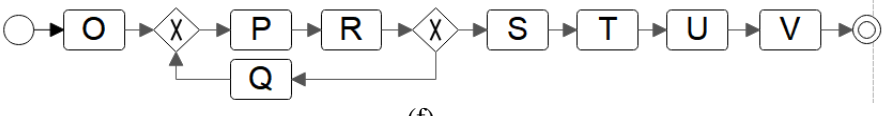

$$
\begin{aligned}
& O \rightarrow O x \rightarrow \frac{P}{Q} \rightarrow \frac{R}{S} \rightarrow \mathrm{T} \rightarrow \mathrm{T} \rightarrow \mathrm{V} \rightarrow(0
\end{aligned}
$$

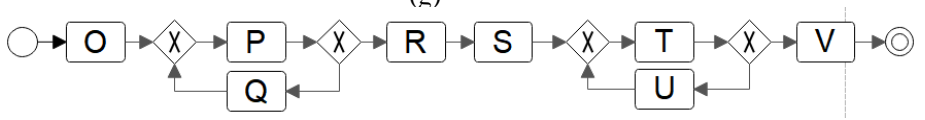

Gambar. 9. Model proses bisnis dengan variasi perulangan.

$$
\rightarrow \text { O }
$$

Gambar. 10. Model proses bisnis dengan kombinasi logika bercabang. 
Nilai kesamaan pada similarity struktur diukur dengan membandingkan aspek yang serupa pada model proses BPMN, seperti label task activity, connector, dan gateway (percabangan) yang sama. Model proses secara struktural dihitung similaritynya menggunakan rumus Jaccard Coefficient Similarity pada (1).

$$
\text { Jacc } \operatorname{sim}=\frac{x \bigcap y}{x \bigcup y}
$$

Berdasarkan dataset pada figure 2 sampai 10, didapatkan event $\log$ yang ditunjukan pada tabel. 1 berikut.

TABEL 1. EVENT LOG

\begin{tabular}{|c|c|c|}
\hline No & Figure & Event Log \\
\hline 1 & $2 \mathrm{a}$ & $\mathrm{O}$ \\
\hline 2 & $2 b$ & OP \\
\hline 3 & $2 \mathrm{c}$ & OPQ \\
\hline 4 & $3 a$ & OPQR, ORPQ \\
\hline 5 & $3 b$ & $\begin{array}{l}\text { OPRSQ, ORPSQ, ORSPQ, OSPRQ, } \\
\text { OSRPQ, OPSRQ }\end{array}$ \\
\hline 6 & $4 a$ & $\begin{array}{l}\text { OPRQST, ORPSQT, ORSPQT, OSPRQT, } \\
\text { OSRPQT, OPSRQT }\end{array}$ \\
\hline 7 & $4 b$ & $\begin{array}{l}\text { OPRQSTU, ORPSQTU, ORSPQTU, } \\
\text { OSPRQTU, OSRPQTU, OPSRQTU }\end{array}$ \\
\hline 8 & $4 c$ & $\begin{array}{l}\text { OPRQSTUV, ORPSQTUV, ORSPQTUV, } \\
\text { OSPRQTUV, OSRPQTUV, OPSRQTUV }\end{array}$ \\
\hline 9 & $5 a$ & $\begin{array}{l}\text { OPQRSTUV, OPQSRTUV, OPRQSTUV, } \\
\text { OPRSQTUV, OPSQRTUV, OPSRQTUV, } \\
\text { OQPRSTUV, OQPSRTUV, OQRPSTUV, } \\
\text { OQRSPTUV, OQSPRTUV, OQSRPTUV, } \\
\text { ORPQSTU, ORPSQTUV, ORQPSTUV, } \\
\text { ORQSPTUV, ORSPQTUV, ORSQPTUV, } \\
\text { OSPQRTUV, OSPRQTUV, OSQPRTUV, } \\
\text { OSQRPTUV, OSRPQTUV, OSRQPTUV }\end{array}$ \\
\hline 10 & $5 b$ & $\begin{array}{l}\text { OPQRST, OPQRTS, OPQSRT, OPQTRS, } \\
\text { OPQTSR, OPRQST, OPRQTS, OPRSQT, } \\
\text { OPRSTQ, OPRTQS, OPRTSQ, OPSQRT, } \\
\text { OPSQTR, OPSRQT, OPSRTQ, OPSRTQ, } \\
\text { OPSTQR, OPSTRQ, OPTQRS, OPTQSR, } \\
\text { OPTRQS, OPTRSQ, OPTSQR, OPTSRQ, } \\
\text { OQPRST, OQPRTS, OQPSRT, OQPSTR, } \\
\text { OQPTRS, OQPTSR, OQRPST, OQRPTS, } \\
\text { OQRSPT, OQRSTP, OQRTPS, OQRTSP, } \\
\text { OQSPRT, OQSPTR, OQSRPT, OQSRTP, } \\
\text { OQSTPR, OQSTRP, OQTPRS, OQTPSR, } \\
\text { OQTRPS, OQTRSP, OQTSPR, OQTSRP, } \\
\text { ORPRST, ORPQTS, ORPSQT, ORPSTQ, } \\
\text { ORPTQS, ORPTSQ, ORQPST, ORQPTS, } \\
\text { ORQSTP, ORQSPT, ORQTSP, ORQTPS, } \\
\text { ORSPQT, ORSPTQ, ORSQPT, ORSQTP, } \\
\text { ORSTPQ, ORSTQP, ORTPQS, ORTPSQ, } \\
\text { ORTQPS, ORTQSP, ORTSPQ, ORTSQP, } \\
\text { OSPQRT, OSPQTR, OSPRQT, OSPRTQ, } \\
\text { OSPTQR, OSPTRQ, OSQPRT, OSQPTR, } \\
\text { OSQRPT, OSQRTP, OSQTRP, OSQTPR, } \\
\text { OSRPQT, OSRPTQ, OSRQPT, OSRQTP, } \\
\text { OSRTPQ, OSRTQP, OSTPQR, OSTPRQ, } \\
\text { OSTQPR, OSTQRP, OSTRPQ, OSTRQP, } \\
\text { OTPQRS, OTPQSR, OTPRQS, OTPRSQ, }\end{array}$ \\
\hline
\end{tabular}

\begin{tabular}{|c|c|c|}
\hline & & $\begin{array}{l}\text { OTPSQR, OTPSRQ, OTQPRS, OTQPSR, } \\
\text { OTQRPS, OTQRSP, OTQSPR, OTQSRP, } \\
\text { OTRPQS, OTRPSQ, OTRQPS, OTRQSP, } \\
\text { OTRSPQ, OTRSQP, OTSPQR, OTSPRQ, } \\
\text { OTSQPR, OTSQRP, OTSRPQ, OTSRQP. }\end{array}$ \\
\hline 11 & $6 a$ & $\begin{array}{l}\text { OQPRSTUV, OQRPSTUV, OQSRPTUV, } \\
\text { OQRSPTUV, OQSPRTUV, OQPSRTUV. }\end{array}$ \\
\hline 12 & $6 b$ & $\begin{array}{l}\text { OQTPRSUV, OQTRPSUV, OQTSRPUV, } \\
\text { OQTRSPUV, OQTSPRUV, OQTPSRUV. }\end{array}$ \\
\hline 13 & $6 c$ & $\begin{array}{l}\text { OQTUPRSV, OQTURPSV, OQTUSRPV, } \\
\text { OQTURSPV, OQTUSPRV, OQTUPSRV. }\end{array}$ \\
\hline 14 & $7 \mathrm{a}$ & $\begin{array}{l}\text { OPQSRUVT, OQPSRUVT, OQSPRUVT, } \\
\text { OSPQRUVT, OSQPRUVT, OPSQRUVT, } \\
\text { OPQSRVUT, OQPSRVUT, OQSPRVUT, } \\
\text { OSPQRVUT, OSQPRVUT, OPSQRVUT }\end{array}$ \\
\hline 15 & $7 \mathrm{~b}$ & $\begin{array}{l}\text { OTQSUVRT, OQPSUVRT, OQSUVPRT, } \\
\text { OSUVPQRT, OSUVQVRT, OPSUVQRT, } \\
\text { OPQSVURT, OQPSVURT, OQSVUPRT, } \\
\text { OSVUPQRT,OSVVUQPRT, } \\
\text { OPSVUVQRT. }\end{array}$ \\
\hline 16 & $7 \mathrm{c}$ & $\begin{array}{l}\text { OPRTQSUV, OPTRQSUV, } \\
\text { OPRTQSVU, OPRQSVU, OQPRTSUV, } \\
\text { OQPTRSUV, OQPRTSVU, OQPTRSVU, } \\
\text { OQSUVPRT, OQSVUPRT, OQSUVPTR, } \\
\text { OQSVUPTR, OSUVPRTQ, OSVUPRTQ, } \\
\text { OSUVPTRQ, OSVUPTRQ, OSUVQPRT, } \\
\text { OSVUQPRT, OSUVQPTR, OSVUQPTR, } \\
\text { OPRTSUVQ, OPTRSUVQ, OPRTSVUQ, } \\
\text { OPTRSVUQ. }\end{array}$ \\
\hline 17 & $8 \mathrm{a}$ & OPQ, ORQ, OSQ. \\
\hline 18 & $8 b$ & $\begin{array}{l}\text { OPQ, ORQ, OSQ, OPRSQ, OPSRQ, } \\
\text { ORPSQ, ORSPQ, OSRPQ, OSPRQ, } \\
\text { OPRQ, OPSQ, ORPQ, ORSQ, OSPQ, } \\
\text { OSRQ. }\end{array}$ \\
\hline 19 & $9 \mathrm{a}$ & OPPPQRSTUV \\
\hline 20 & $9 \mathrm{~b}$ & OPQPQRSTUV \\
\hline 21 & $9 \mathrm{c}$ & OPQRPQRSTUV, OPQRSTUV. \\
\hline 22 & $9 \mathrm{~d}$ & OPQRSPQRSTUV, OPQRSTUV. \\
\hline 23 & $9 \mathrm{e}$ & OPQPRSTUV. \\
\hline 24 & $9 f$ & OQRPQRSTUV. \\
\hline 25 & $9 \mathrm{~g}$ & OQRSPQRTUV. \\
\hline 26 & $9 \mathrm{~h}$ & OQPQRSUVUT. \\
\hline 27 & $10 \mathrm{a}$ & $\begin{array}{l}\text { OPQSURT, OPQSVRT, OPSQRT, } \\
\text { OQPSURT, OQPSVRT, OQSPRT, } \\
\text { OSUQPRT, OSVQPRT, OSUPQRT, } \\
\text { OSVPQRT. }\end{array}$ \\
\hline 28 & $10 \mathrm{~b}$ & OPRS, OQRS, OTUVRS, OTVURS. \\
\hline
\end{tabular}

Dengan menggunakan event log pada tabel 1, dilakukan proses mining dengan menggunakan tiga algoritma yaitu algoritma alpha miner, inductive miner dan causal-net mining. Penerapan algoritma alpha miner didefinisikan pada definisi 1 [10]. 
a. Algoritma Alpha Miner

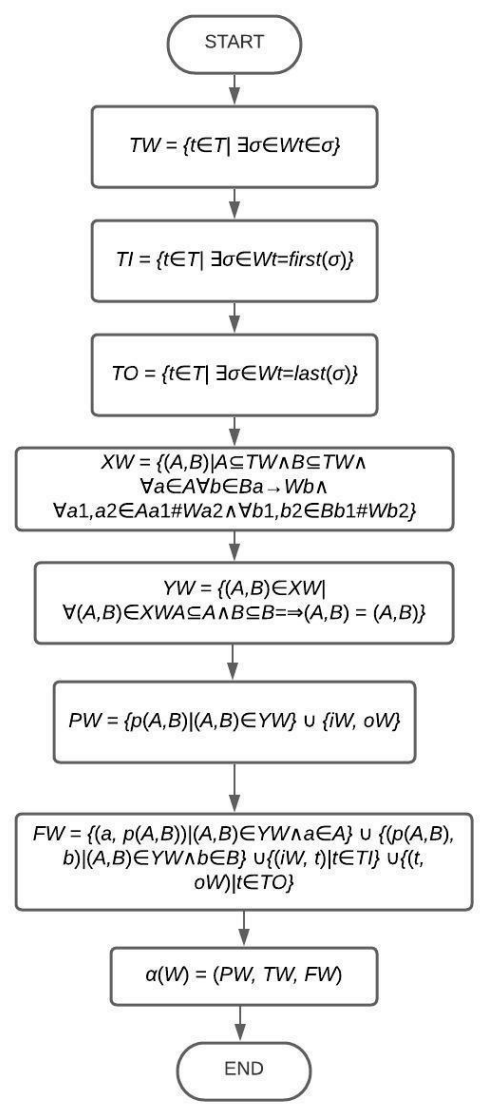

Gambar. 11. Algoritma Alpha Miner

Algoritma inductive miner pada Gambar 11 menjelaskan tahapan-tahapan sebagai berikut [10].

1. Membuat sekumpulan transisi dari event log pada Workflow net $\left(T_{L}\right)$

2. Membuat sekumpulan transisi output dari source place pada Workflow net $\left(T_{I}\right)$

3. Membuat sekumpulan transisi input dari sink place pada Workflow net $\left(T_{O}\right)$

4. Pada langkah ke-4 dan ke-5, algoritma alpha miner membuat set (XW dan YW, masing-masing) yang digunakan untuk menentukan tempat jaring alur kerja yang ditemukan. Pada Langkah 4, algoritma alpha miner menemukan transisi mana yang terkait secara kausal. Jadi, untuk setiap tupel (A, B) di XW, setiap transisi dalam himpunan A secara kausal berhubungan dengan semua transisi di himpunan $\mathrm{B}$, dan tidak ada transisi dalam A (atau B) yang mengikuti satu sama lain dalam beberapa urutan pengaktifan. Batasan ke elemen dalam himpunan $\mathrm{A}$ dan $\mathrm{B}$ ini memungkinkan penambangan yang benar dari konstruksi AND-split / join dan OR-split / join. Perhatikan bahwa OR-split / join membutuhkan fusi tempat.

5. Pada Langkah 5, algoritma alpha miner menyempurnakan set XW dengan hanya mengambil elemen terbesar sehubungan dengan set inklusi. Faktanya, Langkah 5 menetapkan jumlah yang tepat dari tempat yang dimiliki jaring yang ditemukan (tidak termasuk tempat sumber iW dan tempat pembuangan).

6. Place yang sebelumnya diidentifikasi dibuat.
7. Masing-masing place dihubungkan dengan transisi input/output yang bersesuaian.

8. Algoritma kemudian mengembalikan Workflow net yang diperoleh dari langkah-langkah sebelumnya.

b. Algoritma Inductive Miner

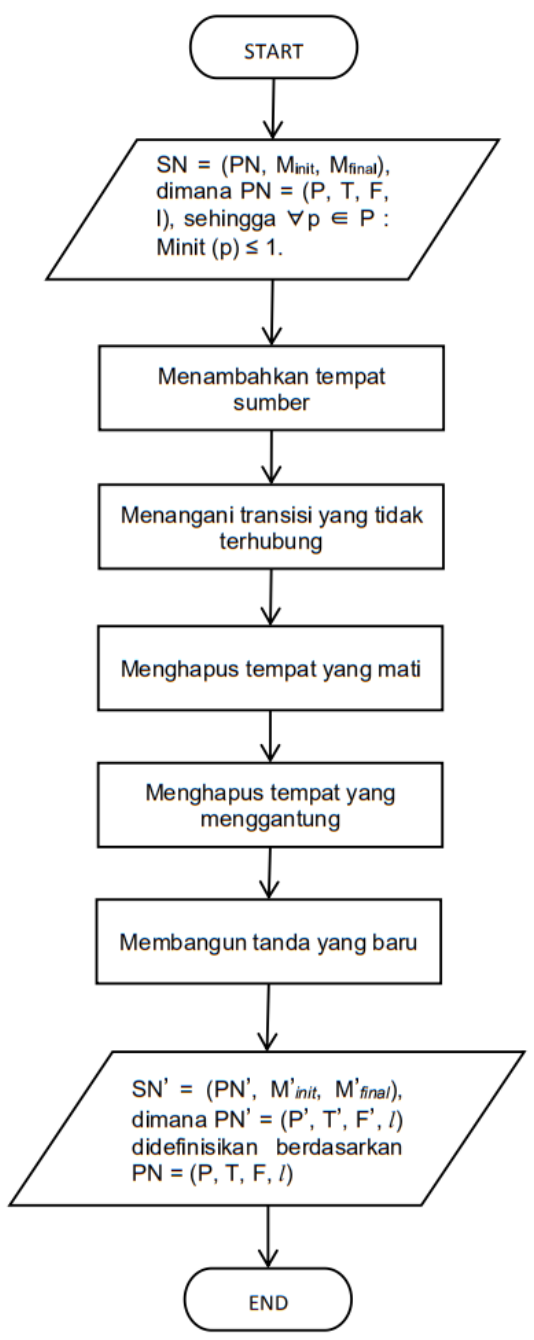

Gambar. 12. Algoritma Inductive Miner

Algoritma inductive miner pada Gambar 12

menjelaskan tahapan-tahapan sebagai berikut [11].

1. Langkah 0: Menambahkan tempat sumber. Tambahkan tempat baru $\mathrm{i} \in \mathrm{P}$, transisi awal baru $\mathrm{t} *$ (perhatikan bahwa $\mathrm{t} *$ tidak memiliki label, karena $\mathrm{t} * / \in \operatorname{dom}(1))$ dan hubungkan dengan busur $(\mathrm{i}, \mathrm{t} *)$. Untuk setiap tempat $\mathrm{p} \in \mathrm{P}$, sehingga Minit $(\mathrm{p})=1$, tambahkan busur $(\mathrm{t} *, \mathrm{p})$.

2. Langkah 1: Menangani transisi yang tidak terhubung. Untuk setiap transisi $\mathrm{t} \in \mathrm{T}$, sehingga $\bullet \mathrm{t}=\emptyset$, tambahkan tempat $\mathrm{p}$, dihubungkan dengan $\mathrm{t}$ dengan busur masuk dan keluar. Tambahkan busur dari transisi awal $\mathrm{t} *$ ke tempat $\mathrm{p}$.

3. Langkah 2: Menghapus tempat mati. Hapus setiap tempat $\mathrm{p} \in \mathrm{P}$ dan transisi dari $\mathrm{p}$ - bersama dengan busur datang, jika tidak ada jalur dari i ke p. Ulangi Langkah 2 sampai tidak ada lagi tempat mati.

4. Langkah 3: Menghapus tempat gantung. Hapus semua tempat $\mathrm{p} \in \mathrm{P}$, sehingga $|\mathrm{p} \bullet|=0$, bersama dengan busur insiden. 
5. Langkah 4: Membangun tanda baru. Misalkan $\mathrm{P}$ adalah himpunan tempat yang dihasilkan, dan $\mathrm{P} * \subseteq \mathrm{P}$ adalah himpunan tempat yang ditambahkan pada Langkah 1 . Kemudian tanda awal dan akhir $\mathbf{M}$ init dan $\mathbf{M}$ akhir didefinisikan sebagai berikut: Untuk semua $p \in P$, sehingga $\mathrm{p}=\mathrm{i}, \mathrm{M}$ init $(\mathrm{p})=0, \mathrm{M}$ init $(\mathrm{i})=1$, untuk semua $\mathrm{p} \in \mathrm{P} *$ menyatakan bahwa $\mathrm{M} f$ inal $(\mathrm{p})=1$, dan untuk semua $\mathrm{p} \in(\mathrm{P} \cap \mathrm{P})$ jumlah token dipertahankan, yaitu, $M$ final $(p)=$ Mfinal $(p)$. Tempat sumber tidak berisi token apa pun dalam penandaan akhir, yaitu $\mathrm{M} \mathrm{f}$ inal $(\mathrm{i})=0$.

c. Algoritma Causal-net Mining

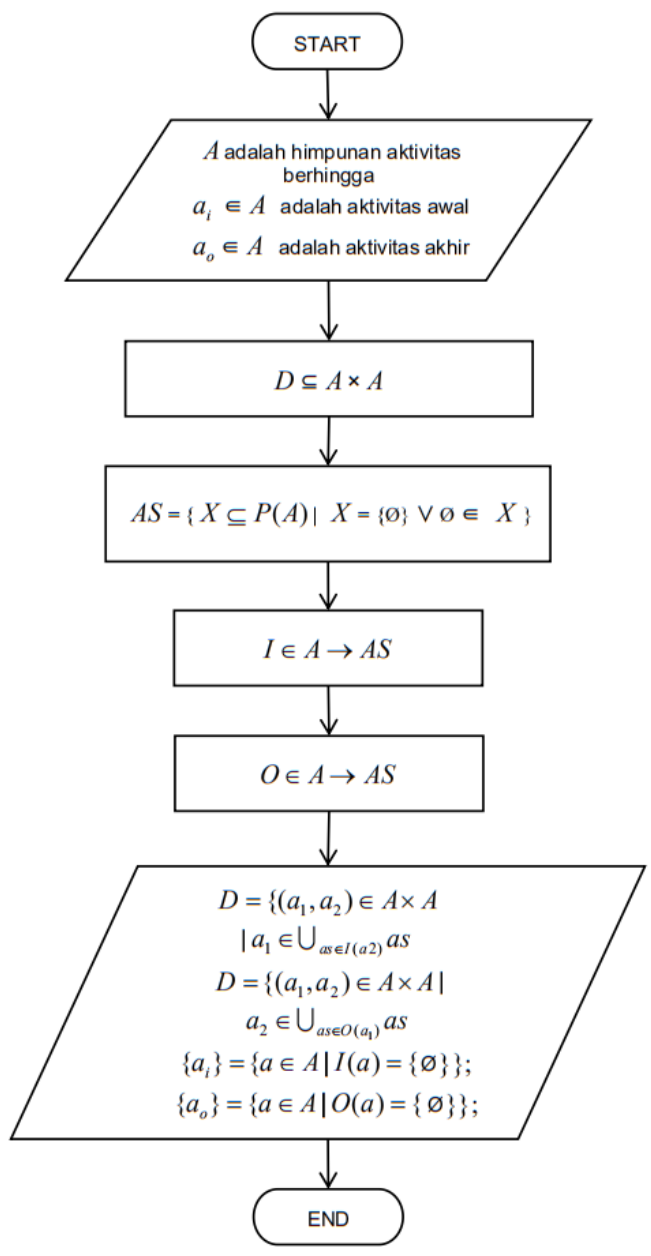

Gambar. 13. Algoritma Causal-net mining

Algoritma causal-net mining pada figure 13 menjelaskan tahapan-tahapan sebagai berikut [5].

$A$ adalah himpunan aktivitas berhingga.

$a_{i} \in A$ adalah aktivitas awal.

$a_{o} \in A$ adalah aktivitas akhir.

$D \subseteq A \times A$ adalah relasi ketergantungan.

$A S=\{X \subseteq P(A) \mid X=\{\varnothing\} \vee \emptyset \in X\} ;$

$I \in A \rightarrow A S$ mendefinisikan himpunan kemungkinan ikatan masukan per aktivitas

$O \in A \rightarrow A S$ mendefinisikan himpunan ikatan

keluaran yang mungkin per aktivitas. seperti,

$$
\begin{aligned}
& D=\left\{\left(a_{1}, a_{2}\right) \in A \times A \mid a_{1} \in \bigcup_{a s \in I(a 2)} a s\right. \\
& D=\left\{\left(a_{1}, a_{2}\right) \in A \times A \mid a_{2} \in \bigcup_{a s \in O\left(a_{1}\right)} a s\right. \\
& \left\{a_{i}\right\}=\{a \in A \mid I(a)=\{\varnothing\}\} ; \\
& \left\{a_{o}\right\}=\{a \in A \mid O(a)=\{\varnothing\}\} ;
\end{aligned}
$$

\section{HASIL DAN PEMBAHASAN}

Proses discovery yang telah dilakukan dengan menggunakan tools ProM. Pada tabel. 2 ditampilkan hasil eksperimen menggunakan ProM dan didapati bahwa terdapat 4 skenario yang tidak cocok dengan model proses pada dataset [7]. Pada algoritma inductive miner dan causal-net mining didapati bahwa hasil discovery berupa BPMN. Sedangkan, pada algoritma alpha miner didapati hasil discovery berupa petri net. Oleh karena itu, petri net dikonversi ke dalam bentuk BPMN menggunakan format file .pnml.

Kami menggunakan figure 7(b) dan dibandingkan dengan hasil discovery figure 7(b) menggunakan algoritma inductive miner untuk diukur similarity strukturalnya. Notasi BPMN terdiri dari activity, connector dan gateaway sehingga dari perbandingan model tersebut didapatkan elemen irisan sebagai berikut:

$\begin{array}{ll}\text { Label task activity } & =8 \\ \text { Connector } & =11 \\ \text { Gateaway } & =2\end{array}$

sedangkan, gabungan dari kedua model, yaitu:

$\begin{array}{ll}\text { Label task activity } & =12 \\ \text { Connector } & =19 \\ \text { Gateaway } & =4\end{array}$

Angka yang didapat, dimasukkan ke dalam rumus perhitungan similarity pada (1)

$$
\text { Jacc } \operatorname{sim}=\frac{8+11+2}{12+19+4}=\frac{21}{35}=0.6
$$

Dengan menggunakan cara yang sama, didapatkan hasil perhitungan similarity secara keseluruhan yang ditunjukan pada tabel. 2 dan tabel. 3 berikut.

TABEL 2. HASIL SimiLARITY KESELURUHAN

\begin{tabular}{|l|c|c|c|}
\hline \multirow{2}{*}{ Dataset } & \multicolumn{3}{|c|}{ Similarity } \\
\cline { 2 - 4 } & Inductive Miner & Alpha Miner & Causal-net Mining \\
\hline Fig 2a & 1 & 1 & 1 \\
\hline Fig 2b & 1 & 1 & 1 \\
\hline Fig 2c & 1 & 1 & 1 \\
\hline Fig 3a & 1 & 1 & 1 \\
\hline Fig 3b & 1 & 1 & 1 \\
\hline Fig 4a & 1 & 1 & 1 \\
\hline Fig 4b & 1 & 1 & 1 \\
\hline Fig 4c & 1 & 1 & 1 \\
\hline Fig 5a & 1 & 1 & 1 \\
\hline Fig 5b & 1 & 1 & 1 \\
\hline Fig 6a & 1 & 1 & 1 \\
\hline Fig 6b & 1 & & \multicolumn{1}{|c|}{} \\
\hline
\end{tabular}


Jurnal Teknologi Informasi dan Terapan (J-TIT) Vol. 7 No. 2 Desember 2020 ISSN: $2580-2291$

\begin{tabular}{|c|c|c|c|}
\hline Fig $6 \mathrm{c}$ & 1 & 1 & 1 \\
\hline Fig 7a & 1 & 1 & 1 \\
\hline Fig 7b & 0.6 & 0.18 & 0.26 \\
\hline Fig 7c & 0.33 & 0.12 & 1 \\
\hline Fig 8a & 1 & 1 & 1 \\
\hline Fig 8b & 0.37 & 0.89 & 0.22 \\
\hline Fig 9a & 1 & Error & 1 \\
\hline Fig 9b & 1 & Error & 1 \\
\hline Fig 9c & 0.43 & 1 & 0.43 \\
\hline Fig 9d & 0.35 & 1 & 0.34 \\
\hline Fig 9e & 1 & 1 & 1 \\
\hline Fig 9f & 1 & 1 & 1 \\
\hline Fig 9g & 1 & 1 & 1 \\
\hline Fig 9h & 1 & 1 & 1 \\
\hline Fig 10a & 0.62 & 0.75 & 0.29 \\
\hline Fig 10b & 1 & 1 & 1 \\
\hline
\end{tabular}

Pada tabel 2 diketahui bahwa terdapat perbedaan similarity pada setiap figure. Usai menyelesaikan perhitungan similarity, didapatkan bahwa ketika nilai similarity antara dua model proses mendekati atau sama dengan 1, maka semakin mirip pula kedua model proses tersebut. Sebaliknya, ketika nilai similarity antara dua model proses dibawah 1, maka semakin rendah tingkat kemiripan kedua model proses.

Figure dengan nilai similarity 1 merupakan model proses dari hasil discovery yang cocok dengan model prose pada dataset. Sedangkan, model proses dengan nilai similarity dibawah 1 merupakan model proses dari hasil discovery yang tidak cocok dengan dataset [7]. Terdapat 17 model proses dengan nilai similarity dibawah 1 . Model proses dengan nilai similarity dibawah 1 dijabarkan pada tabel. 3 berikut.

TABEL 3. HASIL SIMILARITY YANG TIDAK COCOK

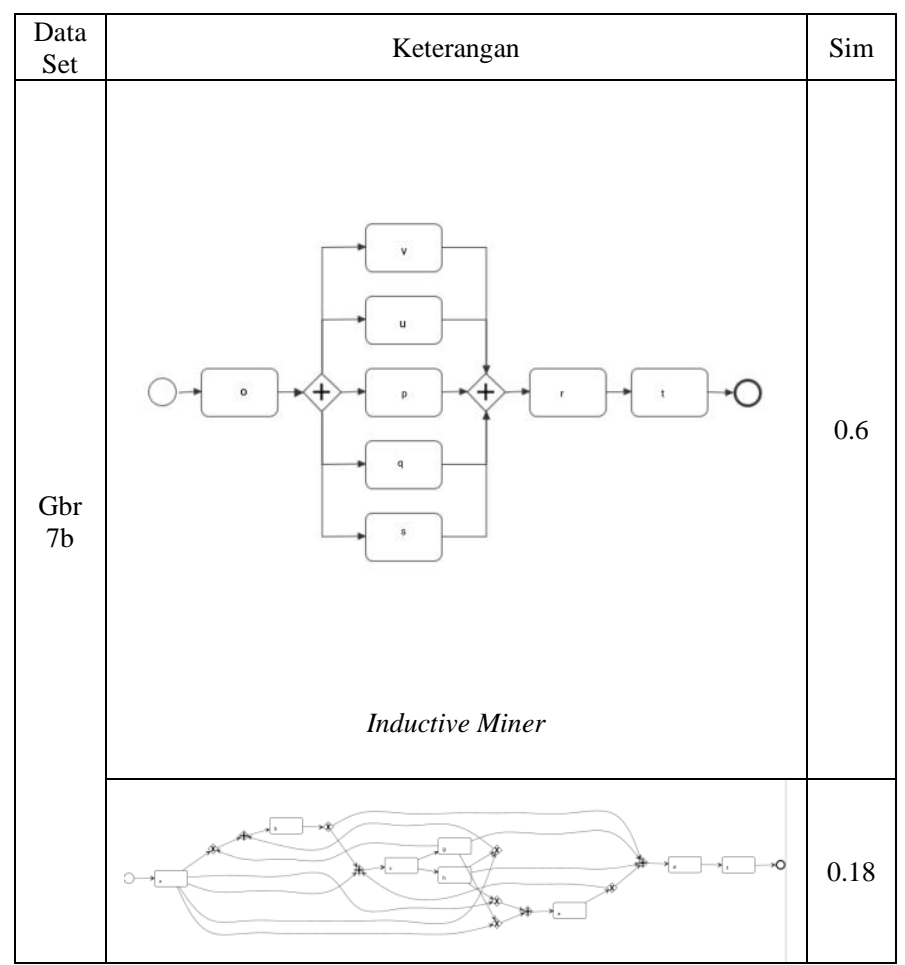




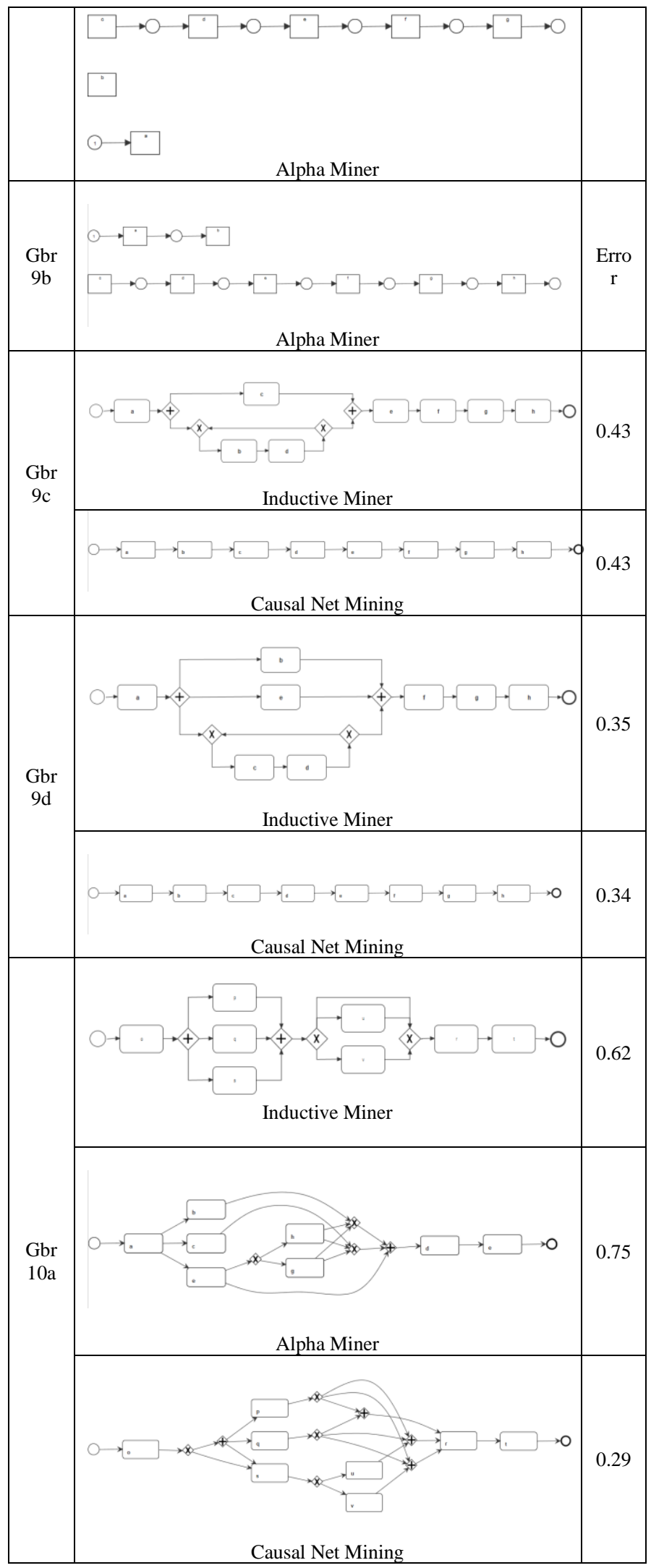

Berdasarkan hasil penelitian pada tabel. 3 setelah kami lakukan perbandingan, diketahui bahwa setiap model proses hasil discovery memiliki nilai similarity yang beragam. Nilai similarity yang didapatkan dipengaruhi oleh 6 komponen, antara lain, jumlah anak panah yang sama, jumlah aktivitas yang sama, jumlah gateaway yang sama, jumlah anak panah kedua model proses setelah digabungkan, jumlah aktivitas kedua model proses setelah digabungkan, dan terakhir jumlah gateaway kedua model proses setelah digabungkan. Pada algoritma alpha miner menghasilkan model roses dalam bentuk petri net, oleh karena itu kami mengubahnya menjadi bentuk BPMN dengan format .pnml menggunakan software Wopad.

Berdasarkan hasil pengukuran similarity diketahui bahwa eksperimen menggunakan algortima alpha miner. Pada figure 8 memiliki nilai tingkat similarity paling tinggi yaitu dengan nilai 0.89 . Sedangkan tingkat similarity paling kecil, didapati pada figure 7 menggunakan alpha miner dengan nilai 0.12. Selain itu, ada pula figure 9a dan 9b dengan hasil similarity yang error dikarenakan saat melakukan discovery mengunakan algoritma alpha miner, model proses yang dihasilkan terpecah menjadi 2 bagian, sehingga tidak bisa dideteksi nilai similarity nya.

\section{KESIMPULAN}

Berdasarkan pembahasan yang telah diuraikan sebelumnya, kami menyimpulkan bahwa pada penelitian ini kami menemukan bahwa, nilai tingkat similarity tertinggi didapati pada figure 8 menggunakan alpha miner dengan nilai 0.89 . Nilai tingkat similarity yang rendah didapati pada figure 7 menggunakan algoritma alpha miner dengan nilai 0.12 . Gambar 2 sampai 6 cocok dengan semua algoritma karena model proses hasil proses mining menggunakan semua algoritma sama persis dengan model proses pada dataset. Gambar 7 paling cocok menggunakan algoritma inductive miner dengan tingkat similarity 0.6. Gambar 8 paling cocok menggunakan algoritma aplha miner dengan tingkat similarity 0.89 . Gambar 9 paling cocok menggunakan algoritma inductive miner dengan tingkat similarity 0.35 . Gambar 10 paling cocok dengan algoritma alpha miner dengan tingkat similarity 0.75 .

\section{REFERENSI}

[1] W. N. Rumana, "Pemodelan Dan Simulasi Proses Bisnis Coloured Petri Nets Modeling and Simulation Production Business Process of Steel Industry Through,” pp. 1-93, 2015.

[2] A. A. Hermawan, "Business Process Context Analysis Based on 'Event Log,"' J. Penelit. dan Pengemb. Komun. dan Inform., vol. 4, no. 3, p. $122699,2014$.

[3] P. Porouhan, N. Jongsawat, and W. Premchaiswadi, "Process and deviation exploration through Alpha-algorithm and Heuristic miner techniques," Int. Conf. ICT Knowl. Eng., pp. 83-89, 2014, doi: 10.1109/ICTKE.2014.7001540.

[4] I. Nuritha and E. R. Mahendrawathi, "Structural Similarity Measurement of Business Process Model to Compare Heuristic and Inductive Miner Algorithms Performance in Dealing with Noise," Procedia Comput. Sci., vol. 124, pp. 255-263, 2017, doi: 10.1016/j.procs.2017.12.154.

[5] W. van der Aalst, A. Adriansyah, and B. van Dongen, "Causal Nets: A Modeling Language Tailored towards Process Discovery," Lect. Notes Comput. Sci. (including Subser. Lect. Notes Artif. Intell. Lect. Notes Bioinformatics), vol. 6901 LNCS, pp. 28-42, 2011, doi: 10.1007/978-3-642-23217-6.

[6] M. A. Yaqin, R. Sarno, and S. Rochimah, "Measuring Scalable Business Process Model Complexity Based on Basic Control Structure," Int. J. Intell. Eng. Syst., vol. 13, no. 6, pp. 52-65, 2020, doi: 10.22266/ijies2020.1231.06.

[7] R. Accorsi, T. Stocker, and G. Müller, "On the exploitation of process mining for security audits: The process discovery case," Proc. ACM Symp. Appl. Comput., pp. 1462-1468, 2013, doi: 10.1145/2480362.2480634.

[8] W. M. P. van der Aalst, "Business alignment: Using process mining as a tool for Delta analysis and conformance testing," Requir. Eng., vol. 10, no. 3, pp. 198-211, 2005, doi: 10.1007/s00766-005-0001-x. 
[9] J. Caldeira and F. B. e Abreu, "Software Development Process Mining:," 10th Int. Conf. Qual. Inf. Commun. Technol. Softw., pp. 254-259, 2016, doi: 10.1109/QUATIC.2016.51.

[10] A. K. A. de Medeiros, B. F. van Dongen, W. M. P. van der Aalst, and A. J. M. M. Weijters, "Process mining: Extending the a algorithm to mine short loops," BETA Work. Pap. Ser., no. June, 2004.

[11] A. A. Kalenkova, W. M. P. van der Aalst, I. A. Lomazova, and V. A. Rubin, "Process mining using BPMN: relating event logs and process models," Softw. Syst. Model., vol. 16, no. 4, pp. 1019-1048, 2017, doi: 10.1007/s10270-015-0502-0. 